\title{
Peroxisome proliferator-activated receptor $\gamma$ ligand troglitazone and TRAIL synergistically induce apoptosis
}

\author{
MAKOTO KOYAMA $^{1}$, YOSHIHIRO SOWA ${ }^{1}$, MANO HORINAKA ${ }^{1}$, \\ AHMED E. GODA ${ }^{1,2}$, JUN FUJIWARA ${ }^{1}$ and TOSHIYUKI SAKAI ${ }^{1}$ \\ ${ }^{1}$ Department of Molecular-Targeting Cancer Prevention, Graduate School of Medical Science, Kyoto Prefectural \\ University of Medicine, Kyoto 602-8566, Japan; ${ }^{2}$ Department of Pharmacology and Toxicology, \\ Faculty of Pharmacy, Tanta University, Tanta, Egypt
}

Received September 19, 2013; Accepted October 25, 2013

DOI: $10.3892 /$ or.2013.2868

\begin{abstract}
Tumor necrosis factor-related apoptosis-inducing ligand (TRAIL) is known to cause apoptosis in several types of malignant tumor cells through its interaction with the death domain-containing receptor, death receptor 5 (DR5). In the present study, we showed that co-treatment with troglitazone (TGZ), a synthetic ligand of peroxisome proliferator-activated receptor $\gamma$ (PPAR $\gamma)$, and TRAIL synergistically induced apoptosis through DR5 upregulation in human colon cancer DLD-1 cells. TGZ elevated DR5 expression at the promoter level through the CCAAT/enhancer-binding protein homologous protein $(\mathrm{CHOP})$ binding site. These results suggest that combined treatment with TGZ and TRAIL may be promising as a new therapy against malignant tumors.
\end{abstract}

\section{Introduction}

Tumor necrosis factor-related apoptosis-inducing ligand (TRAIL) is a promising anticancer agent. TRAIL selectively induces apoptosis in malignant tumor cells in vitro and in vivo and has little to no toxicity in normal cells (1-4). There are two main pathways that initiate apoptosis, the extrinsic (death receptor) and the intrinsic (mitochondrial) pathways. TRAIL binds 5 known cell-surface receptors, death receptor 4 (DR4), DR5, decoy receptor 1 (DcR1), DcR2 and osteopro-

Correspondence to: Professor Toshiyuki Sakai, Department of Molecular-Targeting Cancer Prevention, Graduate School of Medical Science, Kyoto Prefectural University of Medicine, KawaramachiHirokoji, Kamigyo-ku, Kyoto 602-8566, Japan

E-mail: tsakai@koto.kpu-m.ac.jp

Abbreviations: TRAIL, tumor necrosis factor-related apoptosisinducing ligand; TGZ, troglitazone; DR5, death receptor 5; CHOP, CCAAT/enhancer-binding protein homologous protein; siRNA, small interfering RNA

Key words: synergistic apoptosis, tumor necrosis factor-related apoptosis-inducing ligand, troglitazone, death receptor 5, CCAAT/ enhancer-binding protein homologous protein tegerin (5-7). Two of these, DR4 and DR5, possess death domains which recruit Fas-associated death domain (FADD) upon TRAIL ligation. These interactions result in the formation of a death-inducing signaling complex (DISC), leading to stimulation of the extrinsic pathway through caspase- 8 and -10 activation. Importantly, it has been shown that DR5 is more abundantly expressed in cancer cells than in normal cells, and that DR5 may contribute more than DR4 to TRAIL-induced apoptosis in cancer cells which express both DRs (8-10). Thus, the induction of DR5 can at least partially contribute to the tumor-selective induction of apoptosis mediated by TRAIL.

Recombinant human TRAIL (rhTRAIL; dulanermin) is currently being tested in clinical trials in patients with refractory malignant tumors. The phase Ia study by Herbst et al, for the treatment of advanced solid tumors or non-Hodgkin's lymphoma, reported that treatment with rhTRAIL as a monotherapy yielded stable disease in 33 out of $71(46 \%)$ patients and partial responses in $2(3 \%)$ patients with chondrosarcoma (11). These data indicate that despite its promising anticancer efficacy, a considerable proportion of patients with advanced malignant tumors do not respond well to TRAIL alone.

Peroxisome proliferator-activated receptor $\gamma$ (PPAR $\gamma)$ is a member of the ligand-dependent nuclear transcriptional factors. It is well known to be highly expressed in adipose tissue and to play important roles in adipocyte differentiation, lipid metabolism and insulin sensitization (12-14). There are several synthetic ligands for PPAR $\gamma$, including those of the thiazolidinedione class such as troglitazone (TGZ), ciglitazone and pioglitazone $(15,16)$. TGZ was previously prescribed for type 2 diabetes mellitus but liver toxicity led to its withdrawal from clinical use in 2003. In addition to its effect on insulin sensitization, TGZ exerts antitumor activity against malignant tumor cells in vitro and in vivo $(17,18)$. Two phase II studies using TGZ were initiated in patients with metastatic colorectal and refractory metastatic breast cancer. However, these clinical trials reported that no objective responses were observed (19,20).

The endoplasmic reticulum (ER) serves several important functions in the maintenance of cellular homeostasis. Perturbations of ER homeostasis affect protein folding and cause ER stress (21). When ER stress is persistent or excessive, it triggers apoptosis. One of the components of the ER 
stress-mediated apoptotic pathway is the CCAAT/enhancerbinding protein homologous protein (CHOP) (22). It has been reported that TGZ causes apoptosis through induction of ER stress in hepatoma cell lines and through CHOP in a non-small cell lung carcinoma cell line $(23,24)$.

In the present study, we demonstrated that combined treatment of the synthetic PPAR $\gamma$ ligand TGZ and TRAIL causes synergistic apoptosis through DR5 induction in several types of cancer cell lines. The elevation of DR5 expression by TGZ is mediated through CHOP induction via ER stress. These results suggest that co-treatment with the DR5 inducer TGZ and TRAIL may be a promising strategy for cancer therapeutics.

\section{Materials and methods}

Cell culture and reagents. Human colon cancer DLD-1 cells were maintained in RPMI-1640. Human osteosarcoma Saos2, human colon cancer HCT116 and human lung cancer A549 cells were maintained in Dulbecco's Modified Eagle's Medium (DMEM). Culture media were supplemented with $10 \%$ fetal bovine serum, L-glutamine $(2 \mathrm{mmol} / \mathrm{l}$ for RPMI-1640 and $4 \mathrm{mmol} / \mathrm{l}$ for DMEM), $100 \mathrm{U} / \mathrm{ml}$ penicillin and $100 \mu \mathrm{g} / \mathrm{ml}$ streptomycin. Cell cultures were incubated at $37^{\circ} \mathrm{C}$ in a humidified atmosphere of $5 \% \mathrm{CO}_{2}$. TGZ and ciglitazone were purchased from Calbiochem. Pioglitazone was kindly provided by Takeda Chemical Industries. Recombinant human DR5/Fc chimera, zVAD-fmk (pan-caspase inhibitor), zIETD-fmk (caspase-8 inhibitor) and zAEVD-fmk (caspase-10 inhibitor) were purchased from R\&D Systems. Soluble recombinant human TRAIL and the PPAR $\gamma$ inhibitor GW9662 were purchased from PeproTech and Alexis Biochemicals, respectively.

Detection of apoptosis. DNA fragmentation was quantified as the percentage of cells with hypodiploid DNA (sub-G1). For flow cytometric analysis, cells were exposed to the agents for the indicated times. The cells were then treated with Triton X-100 and RNase A, and their nuclei were stained with propidium iodide. DNA content was then measured using a FACSCalibur flow cytometer and CellQuest software (Becton-Dickinson). For all assays, 10,000 cells were counted.

Western blot analysis. Western blot analysis was performed as previously described (25). Anti-DR5 (ProSci), anti-XIAP, anti-cIAP-1, anti-survivin (R\&D Systems), anti-Bcl-2, anti-PARP, anti-Bak, anti-Bax, anti-Bcl- $\mathrm{X}_{\mathrm{L}}$, anti-CHOP, anti-GRP78/Bip (Santa Cruz Biotechnology, Inc.), anti-Bid, anti-caspase-8, anti-caspase-10 (MBL), anti-caspase-3 (Cell Signaling Technology, Inc.) and anti- $\beta$-actin (Sigma) antibodies were used. The signal was then developed with Chemilumi-One (Nacalai Tesque) or Immobilon Western (EMD Millipore).

RNA isolation and real-time reverse transcription-polymerase chain reaction (RT-PCR) analysis. RNA isolation and RT-PCR were performed as previously described (26). The GeneAmp 5700 (Applied Biosystems) was used to quantify the expression level of CHOP and DR5 mRNAs normalized to 18S rRNA. Real-time RT-PCR primer probes were purchased from Applied Biosystems.
Transfection and luciferase assay. A series of CHOP or DR5 reporter plasmids, the ER stress response element (ERSE) mutant plasmid $\mathrm{pCHOP} / \mathrm{mt}$ ERSE and the CHOP mutant plasmid pDR5/mtCHOP were described previously (26). DLD-1 cells were seeded at $1 \times 10^{5}$ cells/well in 6-well plates. One day later, cells were transfected with these plasmids or pGVB2 (a vacant control; $1.0 \mu \mathrm{g}$ ) using the DEAE-dextran method and a CellPhect transfection kit (Amersham Pharmacia Biotech). After $24 \mathrm{~h}$, transfected cells were treated with $60 \mu \mathrm{M}$ TGZ for a further $24 \mathrm{~h}$ and then harvested. Luciferase assays were then performed using luciferase assay reagents (Promega Corporation) and a luminometer.

Small interfering RNA (siRNA). The DR5 siRNA was purchased from Sigma. The CHOP and the negative control siRNAs were purchased from Invitrogen Life Technologies. One day before transfection, DLD-1 cells were seeded at $5 \times 10^{4}$ cells/well in 6 -well plates without antibiotics. The CHOP and/or DR5 siRNAs ( $25 \mathrm{nmol} / \mathrm{l})$ were transfected into cells using Lipofectamine RNAiMAX (Invitrogen Life Technologies) according to the manufacturer's instructions. Twenty hours after the transfection, cells were treated with or without $60 \mu \mathrm{M}$ TGZ for $48 \mathrm{~h}$ and then harvested.

Statistical analysis. Statistical evaluation of the data was performed using the Student's t-test for simple comparison between treatments and controls. $\mathrm{P}<0.05$ was considered to indicate a statistically significant difference. Characterization of synergistic interactions was performed using median dose effect analysis in conjunction with a commercially available software program (CalcuSyn; Biosoft).

\section{Results}

TGZ and TRAIL synergistically induce apoptosis in DLD-1 cells. We investigated the effect of combined treatment with TGZ and TRAIL on apoptosis by measuring the sub-G1 population in colorectal cancer DLD-1 cells. While TGZ or TRAIL used as a single agent caused only slight increases in apoptosis, the combination of TGZ and TRAIL markedly promoted apoptosis in dose- and time-dependent manners. This suggested that TGZ functions as a sensitizer for TRAIL-induced apoptosis (Fig. 1A and B). To characterize the nature of the synergistic apoptosis-inducing effects of co-treatment with TGZ and TRAIL, DLD-1 cells were incubated with various concentrations of TGZ and TRAIL at a fixed ratio. The combination index (CI) value for TGZ and TRAIL was $<1.0$, indicating synergistic apoptosis-inducing efficacy (Fig. 1C).

TGZ and TRAIL synergistically induce caspase-dependent and PPAR $\gamma$-independent apoptosis in DLD-1 cells. We next investigated the mechanism of TGZ/TRAIL-induced apoptosis in DLD-1 cells. TGZ and TRAIL cooperated in the activation of caspase- $10,-8$ and -3 , and in the cleavages of Bid and PARP (Fig. 2A). In support of these findings, TGZ/TRAIL-induced apoptosis was blocked by the pan-caspase inhibitor and the caspase-8 and -10 inhibitors (Fig. 2B). To elucidate whether the sensitization to TRAIL-induced apoptosis by TGZ occurred via a specific interaction between 
A

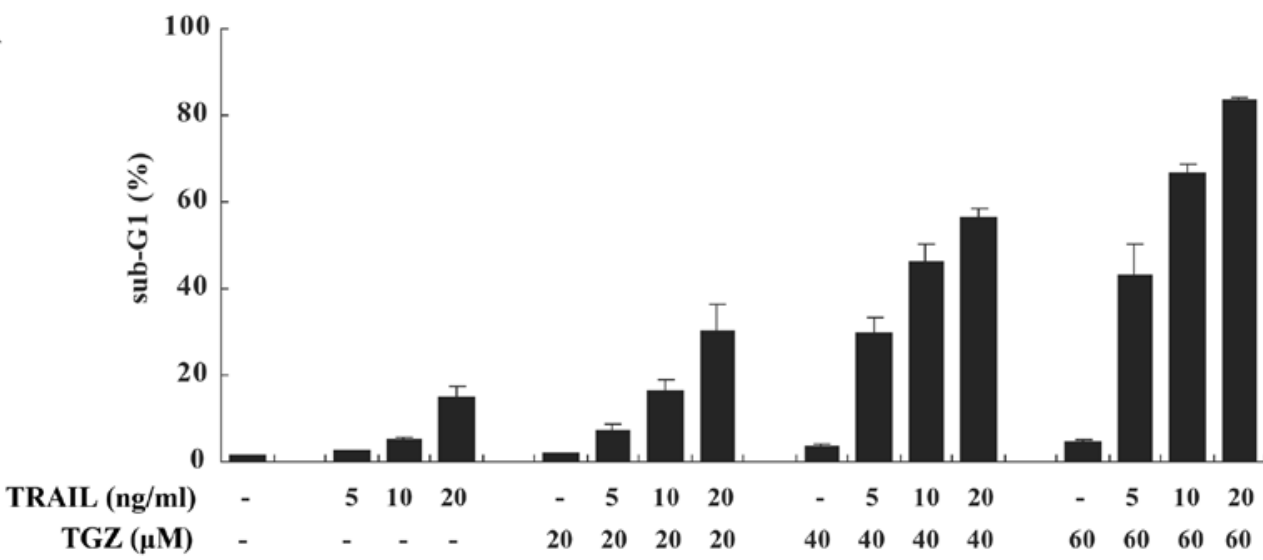

B

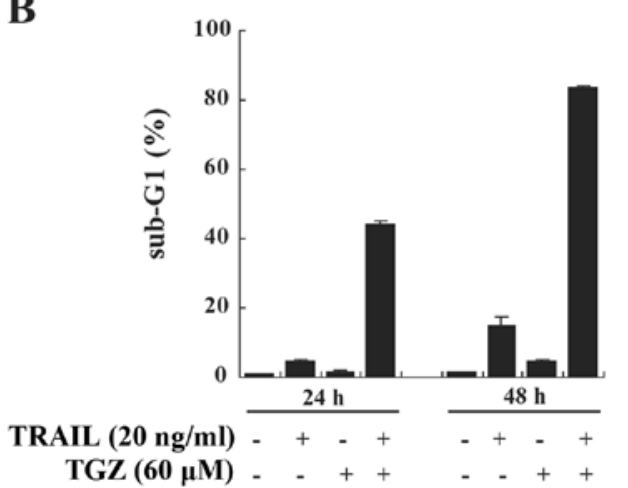

C

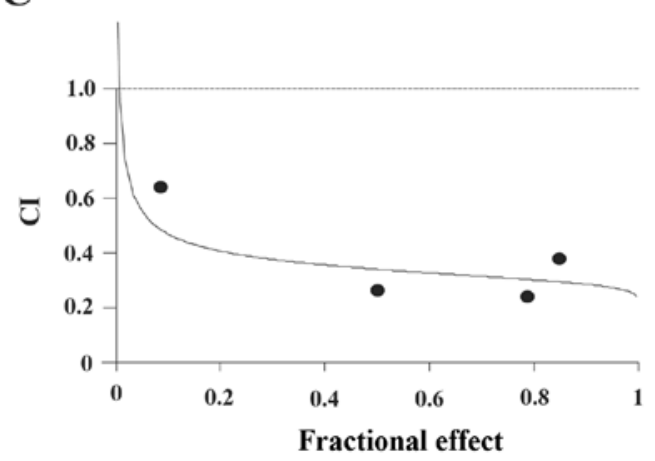

Figure 1. TGZ and TRAIL synergistically induce caspase-dependent apoptosis. (A) DLD-1 cells were exposed to DMSO alone (control) or TGZ with or without TRAIL at the indicated concentrations for $48 \mathrm{~h}$. Apoptosis (sub-G1) was determined by flow cytometry. Columns, means; bars, SD ( $=3$ ). (B) DLD-1 cells were co-treated with TGZ and TRAIL for 24 or 48 h. Apoptosis was determined as above. Columns, means; bars, SD (n=3). (C) DLD-1 cells were exposed to various concentrations of TGZ and TRAIL at a fixed ratio. Apoptosis was determined as above. CI values <1.0 correspond to a synergistic interaction. TGZ, troglitazone; TRAIL, tumor necrosis factor-related apoptosis-inducing ligand; CI, combination index.

TRAIL and its receptors, we used a recombinant human $\mathrm{DR} 5 / \mathrm{Fc}$ chimeric protein, which has a dominant-negative effect by competing with endogenous DR5 for binding to TRAIL. The DR5/Fc chimera efficiently inhibited apoptosis induced by TGZ/TRAIL (Fig. 2B). Additionally, to determine whether TGZ/TRAIL-induced apoptosis was independent of PPAR $\gamma$ activation, we used the PPAR $\gamma$ irreversible antagonist, GW9662. Pretreatment with GW9662 did not attenuate TGZ/TRAIL-induced apoptosis (Fig. 2B). Moreover, unlike TGZ, co-treatment of cells with TRAIL and 2 other PPAR $\gamma$ ligands, pioglitazone or ciglitazone, did not cause synergistic apoptosis (Fig. 2C). These results suggest that TGZ/ TRAIL-induced apoptosis is mediated through the death receptor pathway and is independent of PPAR $\gamma$ activation.

TGZ upregulates CHOP and DR5 expression. CHOP is known to be induced under conditions of ER stress and to play important roles in ER stressor-mediated apoptosis (22). To elucidate whether the mechanism of TGZ-mediated enhancement of TRAIL-induced apoptosis involved this pathway, we examined the expression of CHOP, the ER stress marker GRP78/Bip and apoptosis-related molecules using western blot analysis. We found that TGZ induced the protein expression levels of GRP78/Bip, CHOP and DR5 in a dose-dependent manner (Fig. 3A). Expression of GRP78/Bip was upregulated
$1 \mathrm{~h}$ after treatment with TGZ, while that of CHOP or DR5 was enhanced at $24 \mathrm{~h}$, raising the possibility that ER stress caused by TGZ occurs upstream of increased CHOP and DR5 expression levels (Fig. 3B). Additionally, consistent with previous reports, TGZ decreased anti-apoptotic molecules such as bcl-2 and survivin $(27,28)$ (Fig. 3C). Neither pioglitazone nor ciglitazone increased DR5 and CHOP expression levels (data not shown). These results suggest that synergistic apoptosis induced by co-treatment with TGZ and TRAIL is dependent on ER stress and independent of PPAR $\gamma$ activation.

TGZ increases CHOP and DR5 expression at their promoter activity levels. Next, to elucidate the mechanism of $\mathrm{CHOP}$ or DR5 upregulation by TGZ, we investigated the mRNA levels of these genes using quantitative real-time RT-PCR analysis. TGZ increased the mRNA levels of CHOP and DR5 in a dose-dependent manner (Fig. 4A). To further clarify the molecular mechanism of TGZ-induced upregulation of CHOP and DR5, we analyzed the effect of TGZ on their promoter activities using CHOP or DR5 promoter-luciferase fusion plasmids in a transient assay. TGZ stimulated the promoter activity of $\mathrm{pCHOP} /-150$ (Fig. 4B). It has been shown that the CHOP promoter harbors an ERSE between -93 and -75 bp from the transcription start site, which is activated by an ER stress inducer, tunicamycin (29). Indeed, 

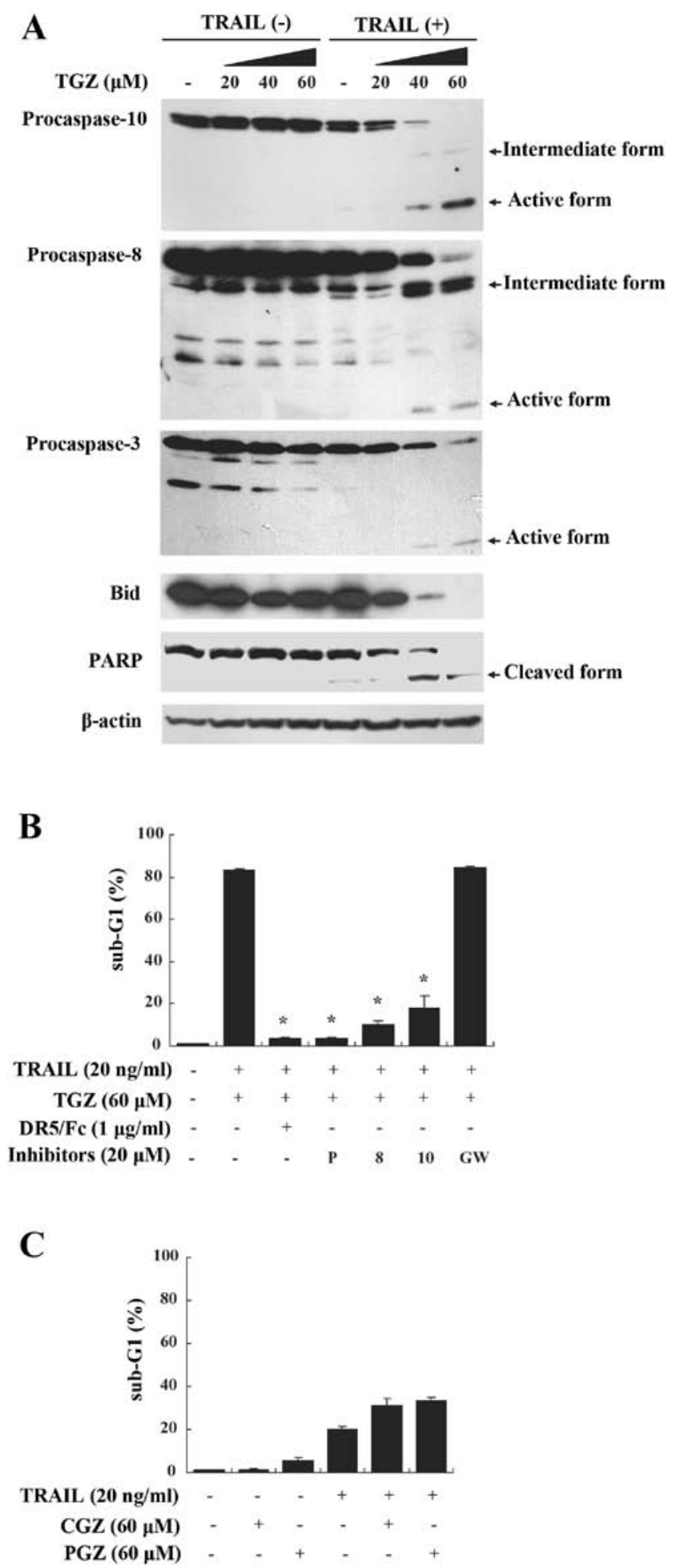

Figure 2. Apoptosis induced by TGZ and TRAIL is mediated through caspase activation and not PPAR $\gamma$. (A) DLD-1 cells were exposed to TGZ at the indicated concentrations with or without $20 \mathrm{ng} / \mathrm{ml}$ TRAIL for $48 \mathrm{~h}$. Activation of caspase-10, - $-8,-3$ and Bid, as well as cleavage of PARP were assessed by western blotting. $\beta$-actin was used as a loading control. (B) DLD-1 cells were pretreated with or without various caspase inhibitors, DR5/Fc or GW9662 for $1 \mathrm{~h}$ followed by the addition of $60 \mu \mathrm{M}$ TGZ and $20 \mathrm{ng} / \mathrm{ml}$ TRAIL for $48 \mathrm{~h}$ Apoptosis was determined as above. P, pan-caspase inhibitor; 10, caspase-10 inhibitor; 8 , caspase-8 inhibitor; GW, GW9662. Columns, means; bars, SD $(n=3) .{ }^{*} \mathrm{P}<0.05$ when compared with cells treated with TGZ and TRAIL. (C) DLD-1 cells were exposed to $60 \mu \mathrm{M} \mathrm{CGZ} \mathrm{or} 60 \mu \mathrm{M}$ PGZ with or without $20 \mathrm{ng} / \mathrm{ml}$ TRAIL for $48 \mathrm{~h}$ and apoptosis was determined as above. Columns, means; bars, SD $(n=3)$. TGZ, troglitazone; TRAIL, tumor necrosis factorrelated apoptosis-inducing ligand.
A

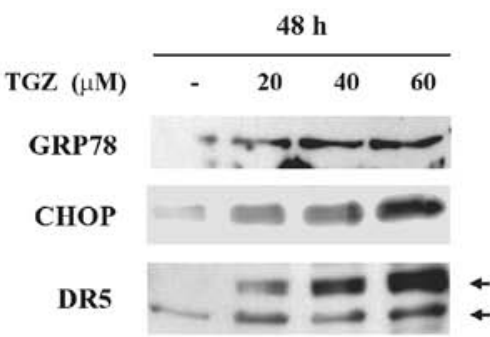

$\beta$-actin

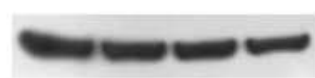

B

TGZ $(60 \mu \mathrm{M})$

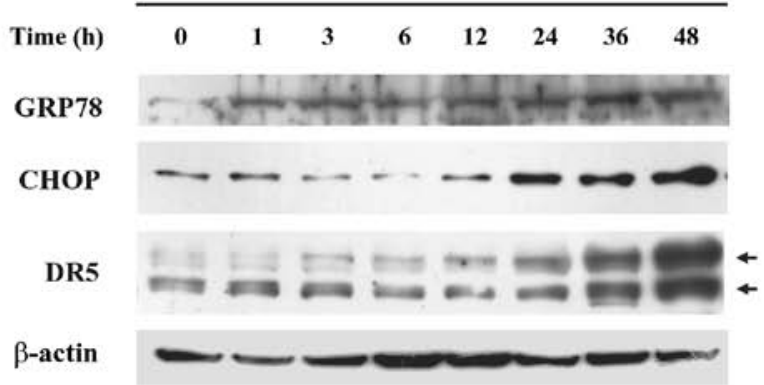

C

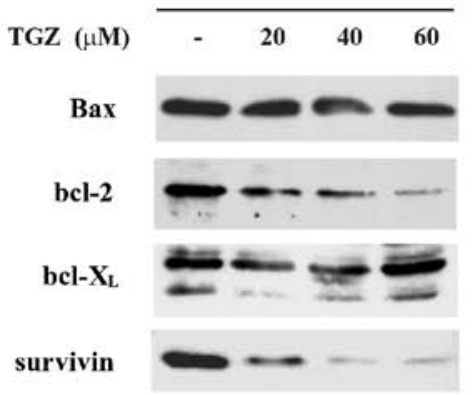

Mcl-1

cIAP-1
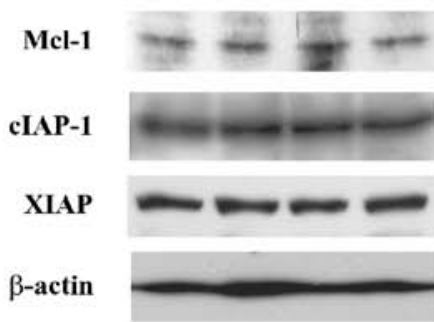

Figure 3. TGZ alters the protein expression levels of ER stress- or apoptosis-related molecules. (A) DLD-1 cells were treated with TGZ at the indicated concentrations for $48 \mathrm{~h}$. The expression of GRP78, CHOP, DR5 and $\beta$-actin (a loading control) were assessed by western blotting. (B) DLD-1 cells were treated with $60 \mu \mathrm{M}$ TGZ for the indicated periods. The expression of GRP78, CHOP, DR5 and $\beta$-actin (a loading control) were assessed by western blotting. (C) DLD-1 cells were treated with TGZ at the indicated concentrations for $48 \mathrm{~h}$. The expression of Bax, bcl-2, bcl- $\mathrm{X}_{\mathrm{L}}$, survivin, Mcl-1, cIAP-1, XIAP and $\beta$-actin (a loading control) were assessed by western blotting. TGZ, troglitazone; CHOP, CCAAT/enhancer-binding protein homologous protein.

mutation of the ERSE abolished the activation of the CHOP promoter by TGZ (Fig. 4B upper). On the other hand, the luciferase activity of pDR5/-347 was significantly increased by TGZ (Fig. 4B lower). Additionally, the promoter region from pDR5/-252 or pDR5/-347, which harbored CHOP mutations, 
A

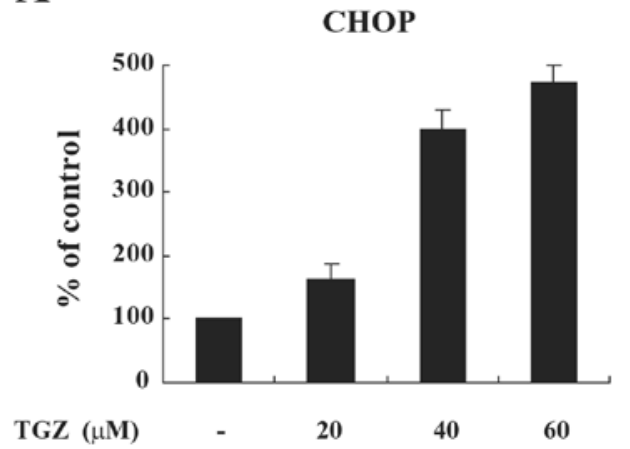

DR5

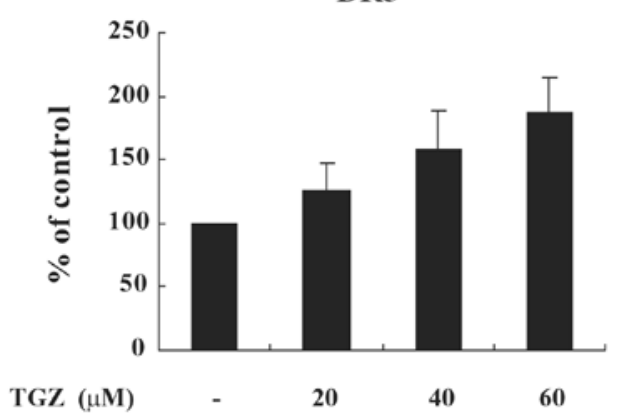

B

Relative luciferase activity (RLU/ $\mu$ g protein)

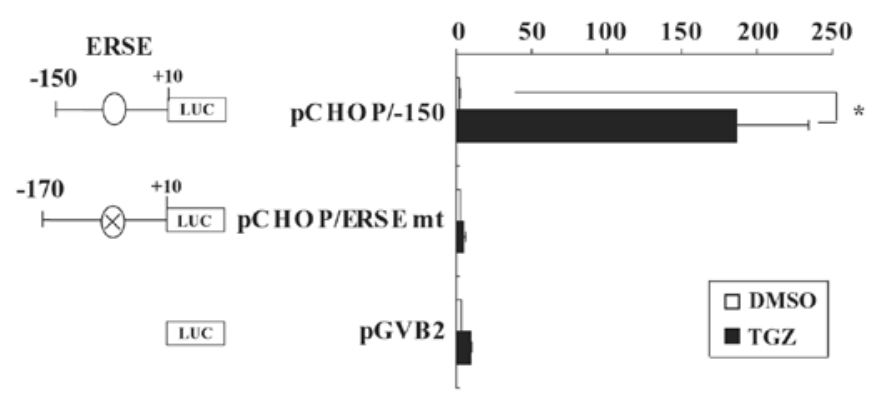

Relative Iuciferase activity (RLU/ $\mu \mathrm{g}$ protein)

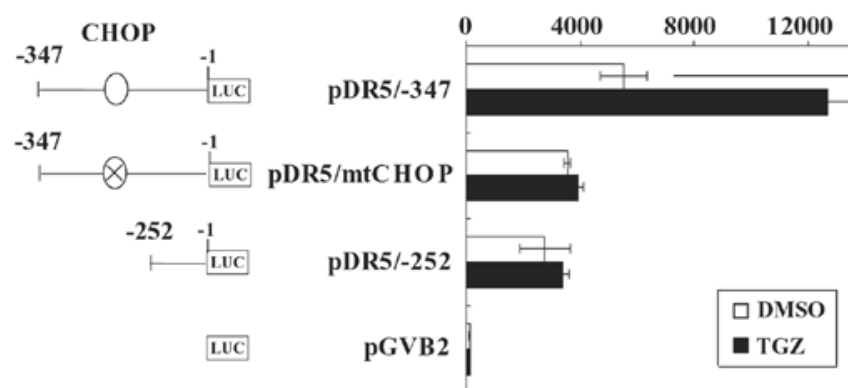

Figure 4. TGZ transcriptionally induces CHOP and DR5. (A) The expression of CHOP and DR5 mRNAs was examined using real-time RT-PCR. The levels of these mRNAs were standardized against that of $18 \mathrm{~S}$ rRNA. Columns, means; bars, SD (n=3). (B) DLD-1 cells were transiently transfected with a series of CHOP reporter plasmids, the ERSE mutant plasmid pCHOP/mtERSE (upper), a series of DR5 reporter plasmids or the CHOP mutant plasmid pDR5/mtCHOP plasmids (lower) as indicated. The cells were treated with $60 \mu \mathrm{M}$ TGZ for $24 \mathrm{~h}$, after which luciferase activity was measured. Columns, means; bars, SD (n=3). ${ }^{*} \mathrm{P}<0.05$. TGZ, troglitazone; CHOP, CCAAT/enhancer-binding protein homologous protein.

did not alter luciferase activity in response to TGZ. These results indicate that TGZ transcriptionally induces CHOP through ER stress, resulting in the upregulation of DR5 at the promoter level.

Upregulation of DR5 and CHOP by TGZ contributes to the enhancement of TRAIL-induced apoptosis. As shown in Fig. 4B, we observed that CHOP is responsible for the transactivation of the DR5 promoter by TGZ. Therefore, we next examined whether CHOP and/or DR5 contributed to TGZ/TRAIL-mediated apoptosis in DLD-1 cells using CHOP and/or DR5 siRNAs. Concomitant with CHOP reduction by CHOP siRNA, TGZ-induced DR5 upregulation was efficiently suppressed when compared with control siRNA (Fig. 5A). In addition, transfection of CHOP and/or DR5 siRNAs, into
DLD-1 cells, at least partially impaired the induction of apoptosis by TGZ. Taken together, these results suggest that TGZ enhances TRAIL-triggered apoptosis through CHOP elevation via ER stress and subsequent DR5 induction (Fig. 5B).

TGZ increases both CHOP and DR5 expression and enhances TRAIL-induced apoptosis in other malignant tumor cells. To investigate whether the effects of co-treatment with TGZ and TRAIL on apoptosis may be observed more generally, other malignant tumor cell lines such as Saos2, HCT116 and A549 were similarly assayed. We found that TGZ induced DR5 and CHOP expressions and sensitized TRAIL-induced apoptosis in these cell lines (Fig. 6A and B). These results suggest that TGZ sensitizes TRAIL-induced apoptosis through CHOP and DR5 induction in various malignant tumor cells. 
A
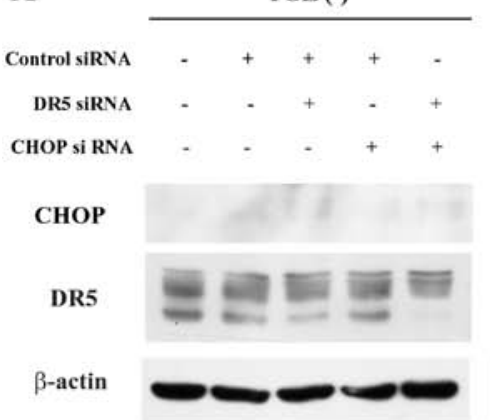
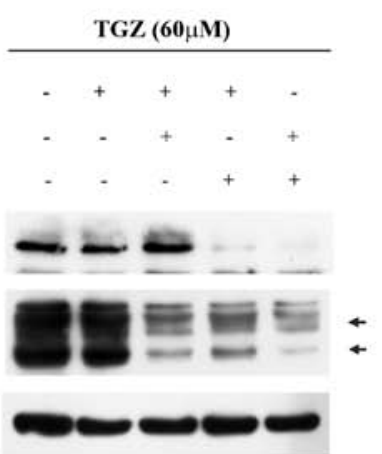

B

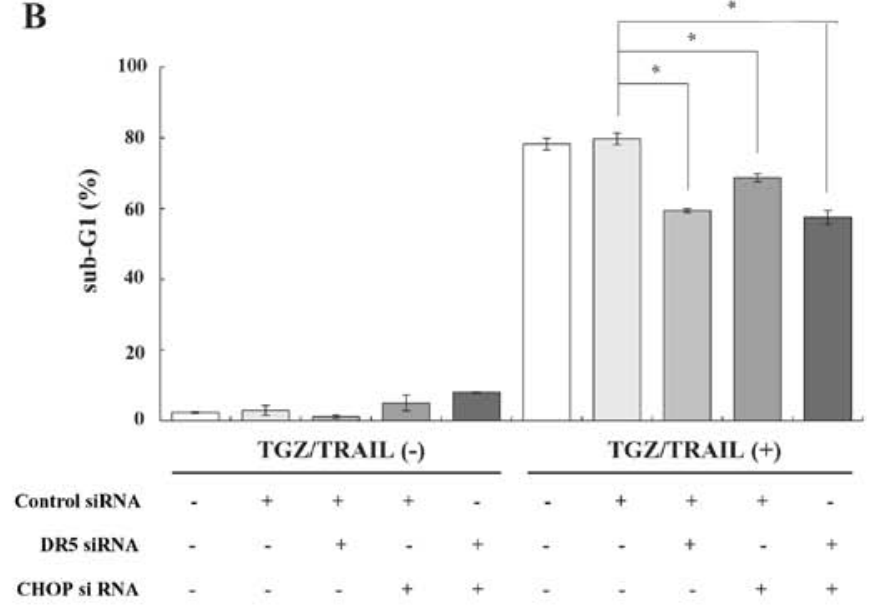

Figure 5. CHOP and DR5 are involved in TGZ/TRAIL-induced apoptosis. (A) DLD-1 cells were transfected with siRNAs as indicated. Twenty-four hours after transfection, cells were treated with DMSO alone or $60 \mu \mathrm{M}$ TGZ for $48 \mathrm{~h}$. The expression levels of DR5, CHOP and $\beta$-actin (a loading control) were assessed by western blotting. (B) DLD-1 cells were transfected with siRNAs as indicated. Twenty-four hours after transfection, cells were treated with or without a combination of $60 \mu \mathrm{M}$ TGZ and $20 \mathrm{ng} / \mathrm{ml}$ TRAIL for $48 \mathrm{~h}$. Apoptosis was determined as above. Columns, means; bars, SD (n=3). "P<0.05. CHOP, CCAAT/ enhancer-binding protein homologous protein; TGZ, troglitazone; TRAIL, tumor necrosis factor-related apoptosis-inducing ligand; siRNA, small interfering RNA.

A

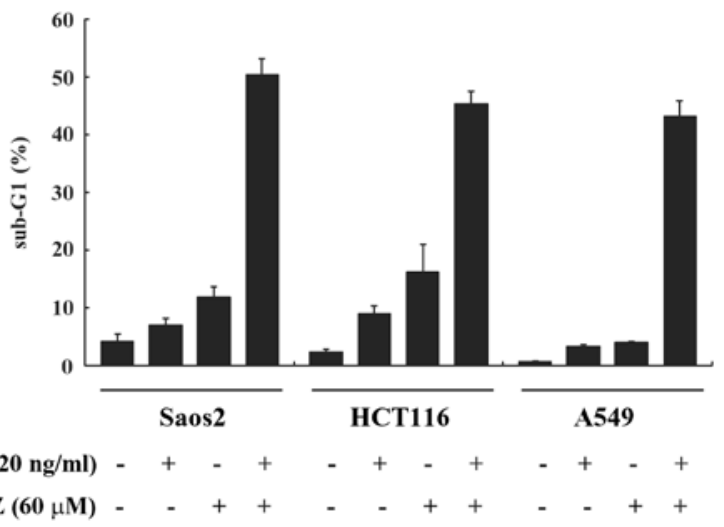

B

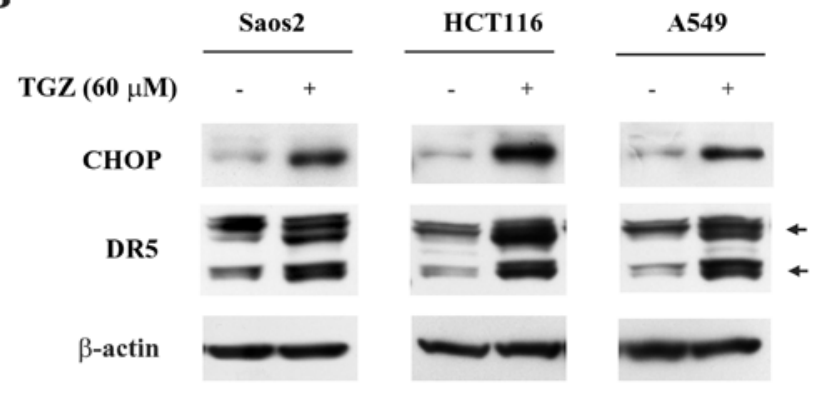

Figure 6. TGZ/TRAIL induces synergistic apoptosis in multiple malignant tumor cell lines. (A) Saos2, HCT116 and A549 cells were treated with $20 \mathrm{ng} / \mathrm{ml}$ TRAIL and/or $60 \mu \mathrm{M}$ TGZ for $48 \mathrm{~h}$ and apoptosis was determined as above. Columns, means; bars, SD (n=3). (B) Saos2, HCT116 and A549 cells were treated with $60 \mu \mathrm{M}$ TGZ for $48 \mathrm{~h}$, and the protein expression levels of CHOP, DR5 or $\beta$-actin (a loading control) were assessed by western blotting. TGZ, troglitazone; TRAIL, tumor necrosis factor-related apoptosis-inducing ligand; CHOP, CCAAT/enhancer-binding protein homologous protein.

\section{Discussion}

In cancer therapeutics, it is essential to induce apoptosis specifically in malignant tumor cells but not in normal cells. In this regard, TRAIL has been highlighted as a promising anticancer agent due to its ability to selectively induce apoptosis in malignant tumor cells. However, some tumor cells are resistant to TRAIL-induced apoptosis and the exact mechanisms of resistance have yet to be fully elucidated. A large number of studies have clarified some of the molecular mechanisms of sensitivity or resistance to TRAIL. DcR1, DcR2 and osteoprotegerin inhibit TRAIL binding by competing with DR4 or DR5, suggesting that resistance to TRAIL occurs at its receptor level (30-32). Indeed, transient overexpression of DR5 in TRAIL-resistant cancer cells restores TRAIL sensitivity (33). DR5 expression in a number of human T-cell acute lymphoblastic leukemia Jurkat sub-clones has also been highly correlated with sensitivity to TRAIL (34). In the present study, we demonstrated that TGZ enhanced TRAIL-induced apoptosis through DR5 elevation, suggesting that this combined treatment is a rational strategy that targets DR5 in combination with TRAIL-based therapy.

The antitumor efficacy of TRAIL has been shown to be enhanced by a variety of anticancer agents, including conventional chemotherapeutic and molecular-targeted drugs (35). On the basis of these preclinical data, a clinical phase Ib study of rhTRAIL with rituximab by Yee et al was initiated in patients with relapsed low-grade non-Hodgkin's lymphoma. The co-treatment was active in this disease, yielding $2(25 \%)$ complete responses, 1 (13\%) partial response and $5(63 \%)$ stable diseases (36). In a clinical phase Ib study by Soria $\mathrm{et} \mathrm{al}$, patients with non-small cell lung cancer (NSCLC) were treated with rhTRAIL, combined with the antitumor drugs, paclitaxel, carboplatin and bevacizumab. The combination was well toler- 
ated and $1(4 \%)$ complete response, $13(54 \%)$ partial responses and $9(38 \%)$ stable diseases were observed (37). The results of this phase Ib trial led the researchers to conduct a phase II study using this combination therapy in patients with NSCLC. However, they reported that the combined treatment did not improve clinical outcome (38). Therefore, to enhance the antitumor activity of TRAIL, more rational therapeutic strategies based on molecular mechanisms underlying sensitivity and resistance to TRAIL should be developed.

We previously showed that the proteasome inhibitor MG132 or the antibiotic tunicamycin increased DR5 expression at the transcriptional level via CHOP induction in association with significant sensitization of malignant tumor cells to TRAIL-induced apoptosis $(39,40)$. The present study described that TGZ, at least in part, enhances TRAIL-induced apoptosis through CHOP induction via ER stress and subsequent DR5 elevation at their transcriptional levels. Collectively, these findings indicate that a variety of agents that upregulate CHOP possess the ability to increase DR5 expression and thus enhance TRAIL-induced apoptosis. Additionally, these agents may reduce the minimal effective dose of TRAIL required for apoptosis induction in tumor cells and therefore reduced the side-effects caused by high doses of TRAIL. However, for clinical application, it remains to be elucidated whether MG132 or tunicamycin can be given safely without toxicity to normal tissues. The present results suggest that TGZ remains promising as a DR5 inducer when combined with TRAIL and the fact that TGZ was clinically used for type 2 diabetes mellitus for several years may lend a further advantage for safety, although hepatic toxicity caused by TGZ led to its withdrawal from clinical use $(41,42)$.

In conclusion, we have shown that TGZ induces ER stress, resulting in CHOP and DR5 expression and subsequent TGZ-mediated synergism of TRAIL-induced apoptosis in a variety of human malignant tumor cells. These results suggest that the combination of TGZ and TRAIL may be promising for treating a broad spectrum of malignant tumors in a clinical environment.

\section{Acknowledgements}

This study was supported by a Grant-in-Aid from the Japanese Ministry of Education, Culture, Sports, Science and Technology.

\section{References}

1. Wiley SR, Schooley K, Smolak PJ, et al: Identification and characterization of a new member of the TNF family that induces apoptosis. Immunity 3: 673-682, 1995.

2. Ashkenazi A,Pai RC, Fong S, et al: Safety and antitumor activity of recombinant soluble Apo2 ligand. J Clin Invest 104: 155-162, 1999.

3. Keane MM, Ettenberg SA, Nau MM, Russell EK and Lipkowitz S: Chemotherapy augments TRAIL-induced apoptosis in breast cell lines. Cancer Res 59: 734-741, 1999.

4. Schow P, Hooley J, Sherwood S, et al: Differential hepatocyte toxicity of recombinant Apo2L/TRAIL versions. Nat Med 7: 383-385, 2001

5. Pan G, O'Rourke K, Chinnaiyan AM, et al: The receptor for the cytotoxic ligand TRAIL. Science 276: 111-113, 1997.

6. Pan G, Ni J, Wei YF, Yu G, Gentz R and Dixit VM: An antagonist decoy receptor and a death domain-containing receptor for TRAIL. Science 277: 815-818, 1997.

7. Wang S and El-Deiry WS: TRAIL and apoptosis induction by TNF-family death receptors. Oncogene 22: 8628-8633, 2003.
8. Kelley RF, Totpal K, Lindstrom SH, et al: Receptor-selective mutants of apoptosis-inducing ligand $2 /$ tumor necrosis factorrelated apoptosis inducing ligand reveal a greater contribution of death receptor (DR) 5 than DR4 to apoptosis signaling. J Biol Chem 280: 2205-2212, 2005.

9. Ichikawa K, Liu W, Zhao L, et al: Tumoricidal activity of a novel anti-human DR5 monoclonal antibody without hepatocyte cytotoxicity. Nat Med 7: 954-960, 2001.

10. Koornstra JJ, Kleibeuker JH, van Geelen CM, et al: Expression of TRAIL (TNF-related apoptosis-inducing ligand) and its receptors in normal colonic mucosa, adenomas, and carcinomas. J Pathol 200: 327-335, 2003.

11. Herbst RS, Eckhardt SG, Kurzrock R, et al: Phase I dose-escalation study of recombinant human Apo2L/TRAIL, a dual proapoptotic receptor agonist, in patients with advanced cancer. J Clin Oncol 28: 2839-2846, 2010.

12. Tontonoz P, Hu E, Graves RA, Budavari AI and Spiegelman BM: mPPAR gamma 2: tissue-specific regulator of an adipocyte enhancer. Genes Dev 8: 1224-1234, 1994.

13. Tontonoz P, Hu E and Spiegelman BM: Stimulation of adipogenesis in fibroblasts by PPAR $\gamma 2$, a lipid-activated transcription factor. Cell 79: 1147-1156, 1994.

14. Chawla A, Schwarz EJ, Dimaculangan DD and Lazar MA: Peroxisome proliferator-activated receptor (PPAR) gamma: adipose-predominant expression and induction early in adipocyte differentiation. Endocrinology 135: 798-800, 1994.

15. Fujiwara T, Yoshioka S, Yoshioka T, Ushiyama I and Horikoshi H: Characterization of new oral antidiabetic agent CS-045. Studies in $\mathrm{KK}$ and $\mathrm{ob} / \mathrm{ob}$ mice and Zucker fatty rats. Diabetes 37 : 1549-1558, 1988 .

16. Lehmann JM, Moore LB, Smith-Oliver TA, Wilkison WO, Willson TM and Kliewer SA: An antidiabetic thiazolidinedione is a high affinity ligand for peroxisome proliferator-activated receptor $\gamma($ PPAR $\gamma)$. J Biol Chem 270: 12953-12956, 1995.

17. Kubota T, Koshizuka K, Williamson EA, et al: Ligand for peroxisome proliferator-activated receptor $\gamma$ (troglitazone) has potent antitumor effect against human prostate cancer both in vitro and in vivo. Cancer Res 58: 3344-3352, 1998.

18. Grommes C, Landreth GE and Heneka MT: Antineoplastic effects of peroxisome proliferator-activated receptor $\gamma$ agonists. Lancet Oncol 5: 419-429, 2004.

19. Kulke MH, Demetri GD, Sharpless NE, et al: A phase II study of troglitazone, an activator of the PPAR $\gamma$ receptor, in patients with chemotherapy-resistant metastatic colorectal cancer. Cancer J 8: 395-399, 2002.

20. Burstein HJ, Demetri GD, Mueller E, Sarraf P, Spiegelman BM and Winer EP: Use of the peroxisome proliferator-activated receptor (PPAR) $\gamma$ ligand troglitazone as treatment for refractory breast cancer: a phase II study. Breast Cancer Res Treat 79: 391-397, 2003.

21. Xu C, Bailly-Maitre B and Reed JC: Endoplasmic reticulum stress: cell life and death decisions. J Clin Invest 115: 2656-2664, 2005.

22. Oyadomari S and Mori M: Roles of CHOP/GADD153 in endoplasmic reticulum stress. Cell Death Differ 11: 381-389, 2004.

23. Maniratanachote R, Minami K, Katoh M, Nakajima M and Yokoi T: Chaperone proteins involved in troglitazone-induced toxicity in human hepatoma cell lines. Toxicol Sci 83: 293-302, 2005.

24. Satoh T, Toyoda M, Hoshino H, et al: Activation of peroxisome proliferator-activated receptor- $\gamma$ stimulates the growth arrest and DNA-damage inducible 153 gene in non-small cell lung carcinoma cells. Oncogene 21: 2171-2180, 2002.

25. Koyama M, Matsuzaki Y, Yogosawa S, Hitomi T, Kawanaka M and Sakai T: ZD1839 induces p15 $5^{\mathrm{INK} 4 \mathrm{~b}}$ and causes $\mathrm{G}_{1}$ arrest by inhibiting the mitogen-activated protein kinase/extracellular signal-regulated kinase pathway. Mol Cancer Ther 6: 1579-1587, 2007.

26. Koyama M, Izutani Y, Goda AE, et al: Histone deacetylase inhibitors and 15-deoxy- $\Delta^{12,14}$-prostaglandin $\mathrm{J}_{2}$ synergistically induce apoptosis. Clin Cancer Res 16: 2320-2332, 2010.

27. Elstner E, Müller C, Koshizuka K, et al: Ligands for peroxisome proliferator-activated receptor $\gamma$ and retinoic acid receptor inhibit growth and induce apoptosis of human breast cancer cells in vitro and in BNX mice. Proc Natl Acad Sci USA 95: 8806-8811, 1998.

28. Lu M, Kwan T, Yu C, et al: Peroxisome proliferator-activated receptor $\gamma$ agonists promote TRAIL-induced apoptosis by reducing survivin levels via cyclin D3 repression and cell cycle arrest. J Biol Chem 280: 6742-6751, 2005. 
29. Ubeda M and Habener JF: CHOP gene expression in response to endoplasmic-reticular stress requires NFY interaction with different domains of a conserved DNA-binding element. Nucleic Acids Res 28: 4987-4997, 2000.

30. Walczak H, Degli-Esposti MA, Johnson RS, et al: Cloning and characterization of TRAIL-R3, a novel member of the emerging TRAIL receptor family. J Exp Med 186: 1165-1170, 1997.

31. Degli-Esposti MA, Dougall WC, Smolak PJ, Waugh JY, Smith CA and Goodwin RG: The novel receptor TRAIL-R4 induces $N F-\kappa B$ and protects against TRAIL-mediated apoptosis, yet retains an incomplete death domain. Immunity 7 : 813-820, 1997.

32. Emery JG, McDonnell P, Burke MB, et al: Osteoprotegerin is a receptor for the cytotoxic ligand TRAIL. J Biol Chem 273: 14363-14367, 1998.

33. Mitsiades N, Poulaki V, Mitsiades C and Tsokos M: Ewing's sarcoma family tumors are sensitive to tumor necrosis factorrelated apoptosis-inducing ligand and express death receptor 4 and death receptor 5. Cancer Res 61: 2704-2712, 2001.

34. Jang YJ, Park KS, Chung HY and Kim HI: Analysis of the phenotypes of Jurkat clones with different TRAIL-sensitivities. Cancer Lett 194: 107-117, 2003.

35. Hellwig CT and Rehm M: TRAIL signaling and synergy mechanisms used in TRAIL-based combination therapies. Mol Cancer Ther 11: 3-13, 2012.

36. Yee L, Fanale M, Dimick K, et al: A Phase IB safety and pharmacokinetic (PK) study of recombinant human Apo2L/TRAIL in combination with rituximab in patients with low-grade nonHodgkin's lymphoma. J Clin Oncol 25: S460, 2007.
37. Soria JC, Smit E, Khayat D, et al: Phase $1 \mathrm{~b}$ study of dulanermin (recombinant human Apo2L/TRAIL) in combination with paclitaxel, carboplatin, and bevacizumab in patients with advanced non-squamous non-small-cell lung cancer. J Clin Oncol 28: $1527-1533,2010$

38. Soria JC, Márk Z, Zatloukal P, et al: Randomized phase II study of dulanermin in combination with paclitaxel, carboplatin, and bevacizumab in advanced non-small-cell lung cancer. J Clin Oncol 29: 4442-4451, 2011

39. Yoshida T, Shiraishi T, Nakata S, et al: Proteasome inhibitor MG132 induces death receptor 5 through CCAAT/enhancerbinding protein homologous protein. Cancer Res 65: 5662-5667, 2005.

40. Shiraishi T, Yoshida T, Nakata S, et al: Tunicamycin enhances tumor necrosis factor-related apoptosis-inducing ligand-induced apoptosis in human prostate cancer cells. Cancer Res 65: 6364-6370, 2005.

41. Gitlin N, Julie NL, Spurr CL, Lim KN and Juarbe HM: Two cases of severe clinical and histologic hepatotoxicity associated with troglitazone. Ann Intern Med 129: 36-38, 1998.

42. Scheen AJ: Thiazolidinediones and liver toxicity. Diabetes Metab 27: 305-313, 2001. 